\title{
Ensaio
}

\author{
Ester Massó Guijarro \\ Universidad de Granada, Espanha
}

\section{La sexualidad femenina, el holismo epistemológico y la complejidad: reflexiones para la vida contemporánea}

Resumen: Partiendo del reconocimiento de la condición compleja del mundo en la globalización y de la necesaria consideración holística de los fenómenos que se le vinculan, se defenderá aquí una perspectiva de la sexualidad femenina análogamente compleja, desde la sugerencia y la defensa del holismo erótico, y como fuente posible de propuestas y soluciones ante los dilemas y encrucijadas propios de la 'era global'. La problematización de la sexualidad y el erotismo femeninos desde el paradigma holístico de la complejidad servirá de pretexto para la consideración de los problemas globales hoy desde una perspectiva diferente $y$ multidisciplinar, y desde la denuncia de los paradigmas reduccionistas y mono-explicativos.

Palabras clave: holismo epistemológico; sexualidad y erotismo femeninos; globalización; multidisciplinariedad.

Copyright $\odot 2009$ by Revista Estudos Feministas.

\footnotetext{
' Las referencias recogidas de la revista Gazeta de Antropología no llevarán nunca numeración de página, aunque sean citas literales, ya que la misma publicación, en soporte electrónico, no la proporciona.
}

\section{Obertura breve: los problemas}

\begin{abstract}
"Resulta notable que galaxias y astros se constituyan de modo torbellinesco, y que la forma menos incorrecta de representarse el átomo evoque al torbellino, es decir, un embuclamiento recursivo" Edgar MORIN, 1995'

Voy a intentar pergeñar en este artículo un examen
\end{abstract} de la sexualidad femenina desde ciertas perspectivas que resultan especialmente permeables a las ideas rectoras del holismo y del paradigma moriniano de la complejidad, principalmente. Así, trataré de asociar y poner en discusión, a modo de embuclamiento recursivo, análisis y campos en principio disímiles, acaso de ardua confluencia o concurso pero que, sin embargo, pueden presentar en su encuentro, a mi juicio, una ingente riqueza y fructificación. 
2 "La idea de que existe una obligación moral universal de respetar la dignidad humana es reemplazada por la idea de lealtad a un grupo muy amplio: la especie humana" (Richard RORTY, 2000, p. 230).

\footnotetext{
${ }^{3}$ Frente al empleo de la palabra "hombre" como genérico (aún tan común en filosofía, mientras que ya rotundamente recusado en la mayoría de las ciencias sociales), aclaro que prefiero con mucho utilizar el término, más justamente neutro a mi entender, de "persona" o, en su defecto, hablar de hombres y mujeres; sin embargo, al ser ésta una cita textual, se ha de respetar el gusto estilístico de su autor. Aplíquese esta reflexión en todo momento análogo.

Por otra parte, cabe enfatizar que ello no sucede con el término "antropología" y los derivados de la raíz griega "anthropos", perteneciente de hecho al género neutro (y siendo "andros" el propio equivalente del género masculino - varón - en griego).
}

El interés de traer a colación las ideas del holismo y la complejidad parten de una asunción epistemológica frente al mundo actual: me resulta difícil comprenderlo - y aún mucho más difícil proponer alternativas novedosas ante sus problemas - sin partir de ellas, de la pluralidad y la voluntad armónica que implican.

Sin embargo, traigo aquí en estos momentos las perspectivas holística y compleja para su específica aplicación a una cuestión: la sexualidad femenina. Se defenderá el cuerpo femenino como un lugar de holismo erótico (o bien erotismo holístico) y, finalmente, en las conclusiones para el debate se extrapolará esta idea a la conveniencia de contagiar muchos otros ámbitos de acción social y relación humana de esta perspectiva del holismo (recreada desde la sexualidad femenina en sus orígenes) y desde una comprensión compleja y contextual de los fenómenos sociales, que camine constantemente de la mano de lo macro y de lo micro. Así, la afectividad vendrá a ser entre las personas lo que la solidaridad habría de ser entre los pueblos o lo que la justicia debería ser entre los diferentes estados del planeta (la justicia como una lealtad más amplia, diría Rorty); ${ }^{2} y$, en todo ello, puede aprenderse mucho de ciertas enseñanzas que veremos sobre la sexualidad femenina desde el holismo.

\section{Acercándonos al mundo globalizado: el holismo y el paradigma de la complejidad}

Son ya muchas y muchos autores hoy los que se esfuerzan por teorizar y pensar no desde una sola categoría, disciplina o perspectiva, sino desde la suma de una pluralidad de ellas, sobrepasados por los grados de complejidad e interrelación crecientes de nuestros 'mundos', de nuestras sociedades. Siempre hubo un gran nivel de complejidad en todo lo social, pero creo que la intensificación no sólo cuantitativa sino cualitativa de la misma, y además a un ritmo de crecimiento exponencial, es, dicho de un modo muy sencillo, lo que hoy llamamos globalización.

Un ejemplo interesante de esta voluntad plural es el llamado paradigma de la complejidad del filósofo francés Edgar Morin; lo comentaré aquí para, seguidamente y tras discutir sobre la perspectiva compleja y holística de la sexualidad femenina, relacionar ambos enfoques en el último epígrafe. 
${ }^{4}$ GÓMEZ GARCÍA, 1996.

5 GÓMEZ GARCÍA, 1996.

• GÓMEZ GARCÍA, 1996.

7 GÓMEZ GARCÍA, 1996.

${ }^{8}$ GÓMEZ GARCÍA, 1996.

${ }^{9}$ MORIN, 1995.
El método de la complejidad es generado por Morin en aras de lograr la reforma del pensamiento que, juzga él, necesitamos hoy a fin de corregir los enfoques y visiones reduccionistas y simplificadores; 4 el paradigma complejo que debe distinguir y relacionar a la vez.

Hay tres teorías fundamentales en las que se apoya Morin para desarrollar este método: la teoría de la información, la teoría cibernética y la teoría de sistemas, cada una aportando diferentes herramientas heurísticas. Finalmente, Morin hablará de tres principios fundamentales para su propio 'sistema': el principio dialógico ("pone en relación dos términos o nociones antagónicas que a la vez se repelen y son indisociables para comprender una misma realidad"); 5 el principio de recursión (que "supone un bucle generador en el cual el producto/efecto se convierte en productor/causa de lo que lo produce") ${ }^{6}$ y el principio hologramático (que "resalta la característica paradójica de algunos sistemas donde no sólo está la parte en el todo, sino que está el todo en la parte"7 - ésta apela directamente a la idea del holismo, como se verá).

La antropología, pues, - es decir, la concepción de persona - que subyace al paradigma moriniano es asimismo de tipo complejo, cosmo-bio-psico-sociológica, articulando physis, bios y ánthropos: "construye una antropología cimentada por abajo en lo cósmico y lo biológico y, por arriba, abierta a lo imaginario, al mito y la magia".

Morin considera que son cuatro polos los que, en una relación sistémica, generan la red de interrelaciones que da lugar a la 'totalidad antropológica': el sistema genético, el cerebral, el sociocultural y el ecosistema; en palabras de Morin:

Nos hace falta, pues, insistir en el doble arraigo del hombre, en el Cosmos físico y en la esfera viviente, al mismo tiempo que en su doble desarraigo con respecto al uno y a la otra. El hombre es a la vez plenamente físico y metafísico, plenamente natural y metanatural. Se ha vuelto extraño a aquello de lo que ha surgido y que, al mismo tiempo, continúa siéndole íntimo. ${ }^{9}$

Por otro lado, no puede comprenderse el principio rector del paradigma de la complejidad sin la noción de holismo, que viene a ser casi su médula espinal conceptual, podríamos decir. Veamos algunas definiciones para sostener este punto.

La definición que el Diccionario de la Real Academia Española de la Lengua da de "complejo" es la siguiente: "(del complexus, part. pas. de complecti, enlazar).1. adj. Que se compone de elementos diversos. 2. adj. Complicado (enmarañado, difícil). 3. m. Conjunto o unión de dos o más 
${ }^{10}$ Se han desdeñado dos acepciones más que no vienen al caso.

11 MORIN, 1995.

12 WILSON, 1999.

${ }^{13}$ SEN, 2000.

14 Francisco MASSÓ CANTARERO, 2001; David SERVAN-SCHREIBER, 2003. cosas". ${ }^{10}$ La que nos ofrece de "holista" es: "(de holo - e ismo).1. m. Fil. Doctrina que propugna la concepción de cada realidad como un todo distinto de la suma de las partes que lo componen".

Así pues, la condición holística de la comprensión que debemos ensayar hoy de un mundo tan altamente complejo hace que las nociones de holismo y de complejidad resulten indiscernibles entre sí: comprensión holística de un mundo complejo, por tanto. Como afirma Morin:

Lo que nos hace falta comprender no es la cultura excluyendo la naturaleza, no es el espíritu excluyendo el cerebro; por el contrario, no podemos comprender nuestra naturaleza si excluimos nuestra cultura, nuestro cerebro si excluimos nuestro espíritu; nos hace falta concebir la "unidualidad" compleja de nuestro ser natural-cultural, de nuestro cerebroespíritu, nuestra realidad a la vez natural y metanatural. ${ }^{11}$

La de Morin no es la única muestra acertada de este denuedo por captar el matiz, por no reducir la observación a una sola variable, esfuerzo que muchos pensadores y pensadoras hoy tratan de secundar; así, menciono de forma sucinta otros intentos (algunos más epistemológicos que otros) de practicar teorías abiertas, multidimensionales y complejas, según esquemas multipolares y multimodales (varios polos, modos varios). La idea de la consiliencia de Edward $\mathrm{O}$. Wilson ${ }^{12}$ constituye una noción original a este respecto; Amartya Sen, ${ }^{13}$ en otro ámbito, ha tratado de reflejar esta 'multiplicidad perspectivista' o perspectiva multimodal al estudio y la investigación sobre la igualdad y la libertad de los seres humanos, yendo mucho allá de las monoexplicaciones habituales desde la teoría clásica de la racionalidad (económica).

Desde la misma psicología hoy, que constituye podríamos decir - casi una antropología del individuo (o la persona), ya no se conciben enfoques monológicos, como se puede contrastar en multitud de autores e investigaciones contemporáneos que consideran a sus pacientes y terapias desde sus condiciones sociales, físicas, personales, etc. ${ }^{14}$

Cabe decir que no es cuestión baladí que la ciencia enfermera, nacida en manos de mujeres y aún hoy primordialmente femenina, haya sido tradicionalmente holística de un modo genuino en su método y en su corpus teórico y disciplinar. Florence Nightingale, la madre de la enfermería moderna, afirmaba ya en 1856 reflexiones tan ciertamente revolucionarias como la siguiente:

Se tiene la tendencia a creer que la medicina cura. No es cierto; la medicina es la cirugía de las funciones, 
${ }^{15}$ NIGHTINGALE, 2006. igual que la verdadera cirugía es la cirugía de los órganos y de los miembros; ni la medicina ni la cirugía pueden hacer otra cosa que quitar las obstáculos; ni la una ni la otra curan, solo la naturaleza puede curar [...]. Lo que hacen los cuidados de enfermería en los dos casos es poner al enfermo en las mejores condiciones para que la naturaleza haga en él su obra. ${ }^{15}$

Y según la definición contemporánea de la enfermería, ésta se ocupa de la promoción, conservación y restablecimiento de la salud con atención especial a los factores biológico y psicosocial, y con absoluto respeto a las necesidades y derechos de la persona atendida.

Con esta referencia a una ciencia tradicionalmente femenina (y por cierto, creo que a causa de ello también tradicionalmente menospreciada y ni siquiera considerada ciencia de modo propio), pasamos al siguiente epígrafe sobre la sexualidad femenina desde las perspectivas de la complejidad y del holismo.

\section{Perspectiva compleja de la sexuali- dad femenina: ${ }^{16}$ el cuerpo de la mujer desde el holismo erótico}

"El deseo tiene diez partes: nueve son de la mujer y una del
hombre"
Homero

Desde la tradición occidental del cuño judeocristiano más ortodoxo (siempre las ortodoxias vienen a matar la creatividad) era común considerar la sexualidad femenina como un objeto oscuro, lleno de represiones y suciedades, que debía ser destinado eminentemente al fin procreador ( $y$ por ende a la satisfacción y desahogo del 'guerrero'); pero, muy especialmente, esta sexualidad era considerada, como tantas otras categorías, desde una perspectiva profundamente masculina y patriarcalista, como si la sexualidad femenina fuera casi una burda, incompleta y embrionaria imitación de la sexualidad masculina. Es decir (basta con leer a Freud), el clítoris de la mujer era un 'pene' en miniatura, anhelante y deforme en su pequeñez. El orgasmo en la mujer prácticamente no existía - o no debía hacerlo -, en tanto que el proceso orgásmico femenino es sencillamente distinto al masculino y, por tanto, invisible a aquellos ojos. El deseo de la mujer era menor o era nulo... más un largo etcétera bien conocido (y ya criticado hoy, por fortuna). 
${ }^{17}$ En la respetable Inglaterra de entonces se consideraba que, para que una mujer quedara embarazada, debía tener un orgasmo. Esto significa - y de hecho hay casos documentados - que si una mujer quedaba en estado fruto de una violación... no se castigaba al violador porque se entendía que no había habido forzamiento, ya que por necesidad la mujer había tenido un orgasmo para que sucediera la fecundación. Sin comentarios.

${ }^{18}$ Helen FISHER, 2000.

19 Tantra OSHO, 2003, p. 136.
Y la alternativa a todo esto, por ejemplo en su versión medieval y posmedieval de la persecución a las brujas, (pero también en la decimonónica de la Inglaterra victoriana) ${ }^{17}$ era la completa y (aún peor en sus consecuencias) antítesis: la malvada mujer representante del demonio, ninfómana por definición, transmisora de enfermedades y embaucadora con su inicua lascivia a no se sabe qué terribles pactos con el maligno y 'el sendero de la mano izquierda'.

Aquí pretendo entrar en discusión en torno a la sexualidad femenina desde una perspectiva bien distinta, a saber, desde su concepción como un tipo de sexualidad holística y compleja, superando la mera genitalidad (tanto en lo femenino como en cuanto al falocentrismo preponderante aún hoy) y recuperando ciertas enseñanzas de culturas y tradiciones que, junto a aquellas ortodoxas mayoritarias, mucho más visibles e influyentes en el statu quo de sus épocas, han persistido desde la disidencia, acaso al modo de corrientes subterráneas y bien liberadoras. Así, emplearé principalmente la concepción de la sexualidad femenina desde el pensamiento tántrico o tantrismo, y ofreceré también algunas pinceladas sobre de la noción de la mujer y el erotismo femenino enraizada en espiritualidades antiguas $y$ medievales, visible hoy en determinados restos artísticos y arquitectónicos.

La sexualidad, ese potente e invencible nudo gordiano del ser y la vida, es de hecho uno de los fenómenos donde, primordialmente en su versión femenina, nos hallamos con más interesantes manifestaciones de la idea de holismo de la que hablamos, de integración, complejidad y pensamiento en red, incluso, opuesto a un más masculino pensamiento 'por pasos'. ${ }^{18}$

El tantrismo, tantra o doctrina del sexo tántrico, ancestral espiritualidad enraizada en la India, pone en efecto en la mujer el acento de la mayor potencia sexual: ella puede tener múltiples orgasmos, acumulando más y más energía durante su sucesión, en lugar de perderla de golpe como sucede con la explosión de la eyaculación masculina. Así, el tantrismo promueve enseñar a los hombres - esa parte yang de la unión sexual - a escindir orgasmo y eyaculación, a través de ejercicios de respiración y control físico-corporal, para emular el proceso orgásmico femenino: "La mujer es el polo receptivo - tiene que serlo, porque tiene que ser madre, necesita más energía". ${ }^{19}$

Según el Diccionario de la Real Academia Española de la Lengua, "tantra" (del sánscrito tantra, propiamente, "telar", "urdimbre", palabras por cierto bien evocadoras de holismo y complejidad) es en el hinduismo y en el budismo una colección de textos sagrados que recogen doctrinas, 
20 OSHO, 2003, p. 128, 129.

${ }^{21}$ Éste es el personaje con el que se identificará Mahatma Gandhi, y a quien recurrirá constantemente, para aprender a lidiar su propia batalla espiritual y desarrollar el satyagraha.

${ }^{22}$ Bhagavad Gîtâ , 2005, versículo 9, p. 166.

${ }^{23}$ Kama Sutra, 2000, p. 12 y 13. prácticas y ritos esotéricos, especialmente relacionados con la sexualidad ya que la consideran una de las vías más apropiadas para desarrollar la conciencia espiritual y alcanzar la iluminación a través de la meditación. El sexo tántrico, a la par que el hatha o el raja yoga, por ejemplo, es una forma más entre otras de meditación extremadamente espiritual. Hay de hecho vinculaciones íntimas en el yoga hindú y el tantrismo; éste propone una concepción de la sexualidad meditativa y trascendental, como vía para religarnos a lo divino a través del amante/amado:

Si tu amante o amado no puede hacerse divino, entonces nada en este mundo puede ser divino. Entonces, todas vuestras charlas religiosas no son más que estupideces [...] Tantra es la ciencia de transformar amantes corrientes en compañeros del alma. Ésta es la grandeza del tantra. ${ }^{20}$

Esta comprensión divinizante y compleja de la sexualidad, que la liga a lo nouménico, presenta un alto parentesco con muchos de los versos o sutras del Bhagavad Gîtâ, texto clásico del pensamiento clásico hindú (y donde se exponen los fundamentos del yoga a través del diálogo entre el dios Krishna y el guerrero Arjuna ${ }^{21}$ antes de una batalla) : "Asentado en el cuerpo, emplea y dirige el oído, los ojos, la piel y la lengua, así como la mente, para disfrutar de los objetos de los sentidos (sonido, etc)". ${ }^{22}$ Aquí observamos con nitidez cómo se insta a una vivencia global, compleja, holística y contextualizada de las sensaciones, por supuesto también las sexuales.

Al Bhagavad Gîtâ acompañan libros hoy ya tan populares que se hallan prácticamente desvirtuados, especialmente porque, como sucede con muchos textos antiguos, la profundidad en su comprensión no suele acompañar a su grado de difusión y popularización. El Kama Sutra o el Koka Sastra, textos clásicos y sagrados hindúes, presentados hoy a menudo simplemente como una galería variopinta de posturas sexuales, contienen en su fondo una concepción de la sexualidad y del erotismo compleja, muy desarrollada, vinculada a la esfera de lo divino y, lo más interesante aquí, holista: "Kama es el goce de las cosas materiales a través de los sentidos: oído, tacto, vista, gusto y olfato, [...] Kama es enseñado por los Kama Sutra (versos del deseo) y por la experiencia". ${ }^{23}$

Regresando al tantrismo, éste no sólo ubica la experiencia sexual en un marco meditativo y religioso (en el sentido de re-ligare), sino que realiza una específica incidencia en lo femenino, en el polo femenino y la experiencia sexual femeninas, promoviendo en realidad una vivencia de la sexualidad esencialmente femenina (lenta, meditativa, 
${ }^{24}$ OSHO 2003, p. 136.

${ }^{25}$ KERNER, 2006, p. 85.

${ }^{26}$ KERNER, 2006, p. 86.

${ }^{27}$ KERNER, 2006, p. 85.

incitadora de una mucha mayor contención en la sexualidad masculina a través del aprendizaje, como decía, de la disociación entre orgasmo y eyaculación): "Las raíces del sexo están por todo tu ser [...] El cuerpo de la mujer es todo sexual, y salvo que todo su cuerpo empiece a temblar de placer, que cada célula de su cuerpo esté involucrada, no podrá tener una explosión orgásmica" [la cursiva es mía]. ${ }^{24}$ Éste es el holismo erótico, el erotismo holístico, al que me he venido refiriendo desde el inicio. En el tantra la mujer es el centro, es la poderosa, es la maestra, es la diosa... invirtiéndose los roles de poder y dominación tradicionales (en otros que, sin embargo, no implican la coacción de ninguno), y evidentemente en rotunda oposición de aquellas otras concepciones que menoscababan y escamoteaban, por una u otra razón (bien ensuciándola, por exceso y desvirtuación, bien negándola, como si fuera una proto-sexualidad frente a la masculina) la vivencia femenina de la sexualidad.

Osho es un místico contemporáneo, y un místico podría considerarse una fuente dudosa en determinados círculos científicos (si bien aprovecho para poner en cuestión que la ciencia no deba interaccionar de forma activa con otras disciplinas 'no científicas' e incluso modos distintos de conocimiento, recordando a Feyerabend). Pero el caso es que encontramos que el sexólogo contemporáneo lan Kerner afirma, curiosamente similar a Osho, sobre el orgasmo femenino que "se origina en la región genital y se extiende a menudo por todo el cuerpo" ${ }^{25} \mathrm{y}$, sobre el desenlace, que

los genitales de las mujeres tardan mucho más en recuperar su estado normal, entre cinco y diez minutos. Las mujeres no suelen quedarse dormidas, sus genitales no se vuelven hipersensibles (a excepción del glande); y no pasan por un periodo refractario, sino que les basta con una mínima estimulación para hallarse en condiciones de repetir el proceso desde el principio; ${ }^{26}$ aunque no se trata de una regla exacta, las mujeres suelen experimentar durante el orgasmo entre seis y diez contracciones, mientras que los hombres sólo tienen entre cuatro y seis. ${ }^{27}$

No sólo encontramos, pues, estas ideas en la literatura tántrica, efectivamente de índole espiritualista y mística, o en ciertos pensadores humanistas, sincréticos e híbridos, que se mueven en el paradigma del cristianismo crítico (como Leonardo Boff, al que seguidamente mencionaré). En última instancia, la sexología más revisada (algunos otros nombres proverbiales en el avance de los estudios sobre sexología femenina - y en general - son los de Shere Hite, Alfred Kinsey, Pomeroy y Martín o Arnold Kegel), bien en contra de la falocracia y el falocentrismo ya hoy tan criticados de Sigmund Freud (quien cuestionó sin fundamentos nada menos que 
28 KERNER, 2006, p. 55ss. "Sigmund Freud se hizo famoso por demonizar el clítoris y formular una visión auténticamente falocéntrica de la sexualidad femenina. Difundió la idea de que el clítoris era una fuente inmadura de placer sexual, un mero campo de entrenamiento para el orgasmo vaginal, más 'maduro', que, naturalmente, sólo se alcanzaba mediante la copulación. Lo que resulta especialmente irritante es que en el momento de formular esta teoría Freud tenía un conocimiento claro de la función anatómica del clítoris, y sin embargo optó por difundir su particular visión se la sexualidad femenina, haciendo caso omiso de los conocimientos científicos. Dicho de otro modo, abusó del púlpito" (KERNER, 2006, p. 55). Por desgracia, este "abuso del púlpito" no es nada extraordinario ni infrecuente en el "mundo científico"... más bien, es penosa y significativamente habitual.

${ }^{29}$ Paul FEYERABEND, 1984.

30 Eudald CARBONELL y Robert SALA, 2002.

31 Leonardo BOFF y Rose Marie MURARO, 2004, p. 128.

${ }^{32}$ BOFF y MURARO, 2004, p. 127.

${ }^{33}$ BOFF y MURARO, 2004, p. 88.

${ }^{34}$ Jesús ÁVILA GRANADOS, 2005, p. 674. las funciones del clítoris), ${ }^{28}$ viene a refrendar lo que el tantra lleva proclamando no ya durante siglos, sino durante milenios desde sus albores en la India antigua. Tal vez no ande tan descabellada la propuesta de anarquismo epistemológico feyerabendiano, ${ }^{29}$ por el que la ciencia debe recurrir a la mística para inspirarse y orientarse.

No encontramos ideas similares, pues, sólo en pensamientos orientales, que podrían parecernos más lejanos. Bien al contrario, hallamos que el brasileño Leonardo Boff, ese franciscano de la Tierra, asocia el 'sexo ontológico' y la 'dimensión-ser', por ejemplo, con la humanización - más allá de la hominización ${ }^{30}$ - y con la actitud femenina o, en otras palabras, con el legado histórico más 'tradicionalmente' femenino - la cooperación frente a la competencia, por ejemplo, entre otros aspectos.

Afirma Leonardo Boff que "las más antiguas imágenes sagradas no son de hombres ni de animales. Son 25.000 estatuillas de mujeres grávidas con grandes senos y enormes caderas, las diosas de la fertilidad". ${ }^{31}$ Y esto no es baladí; se considera un hecho reconocido hoy que las matrices de creencias más antiguas rendían culto a la feminidad, divinizándola, por considerar a las mujeres como las generadoras de la vida y por ende llenas de poder.

La diosa madre, la tierra generadora, el origen del todo. El mitólogo Joseph Campbell, en su aproximación - y ordenación cronológica - a las 1500 cosmologías conocidas, constató que las más arcaicas se referían a una diosa y gran madre, identificada con la tierra, que era el origen y el fin de todo, además de

omnidadivosa, omnirreceptiva, y creadora de todas las otras divinidades $y$, directa $\mathrm{O}$ indirectamente, de todos los seres humanos; ${ }^{32}$ María es la única gran diosa de occidente como lo es Kuan Yin del Oriente y lo fue Isis para las antiguas culturas mediterráneas, así como lo es lemanjá para nuestra cultura popular de tradición afrobrasilera. ${ }^{33}$

La figura femenina de la divinidad en el seno del judeocristianismo, tratada oficialmente en el Concilio de Éfeso del año $431,{ }^{34}$ se extendió desde entonces como el 'culto a María' (María como Theotokus, Madre de Dios, en lugar de cómo Cristotokus, Madre de la naturaleza humana de Jesús el Cristo, disparidad central del citado concilio) por todo el mundo occidental, desde la península ibérica a la moderna Turquía (Anatolia):

El culto se basaba en imágenes evocadoras de los cultos a la Diosa madre (Isis, Artemisa, Diana, Kali, Cibeles, etc). Aunque las representaciones procedían de cultos distintos, tanto el tiempo como en el espacio, 
${ }^{35}$ ÁVILA GRANADOS, 2005, p. 674.

36 La famosa montaña de Montserrat, donde se halló una de las deidades negras más populares, es considerada el principal "punto energético" de Europa y a la vez la zona esotérica más importante de Cataluña. Encontramos vírgenes negras también en Andalucía, en Aragón, en Asturias, en Mallorca, en Canarias, en Castilla y León... y un largo etcétera (ÁVILA GRANADOS, 2005, p. 679-686). ${ }^{37}$ ÁVILA GRANADOS, 2005, p. 677.
38 Se prefiere el término "transculturizado" frente a "aculturizado", más común en ciertos ámbitos académicos (cfr. Walter MIGNOLO, 2005). todas ellas eran negras, porque el negro es el compendio de todos los colores, el resumen final de la más profunda sabiduría y la plena ausencia de luz: era la memoria de los orígenes humanos, el útero materno, donde se emprende el primer 'viaje iniciático' de nuestra existencia. ${ }^{35}$

Estas deidades vírgenes negras suelen encontrarse en enclaves considerados 'lugares de poder', ${ }^{36}$ sosteniendo así una antiquísima y milagrosa tradición, vinculada a la fecundidad, sobre la protección de peregrinos y viajeros, la salud infantil, etc. ${ }^{37}$

Opino que estas perspectivas que vengo mencionando de la sexualidad en general, y de la sexualidad femenina en particular, se enraízan en una concepción de éstas desde el holismo y desde la asunción de la complejidad. Éstas son, como es evidente, teorías, visiones y enfoques particulares frente a otros muchos posibles, pero he escogido presentarlos aquí de esta manera porque considero que pueden alimentar tendencias bien interesantes y que ofrecen alternativas milenarias para muchos problemas contemporáneos. A todo esto, repito, es a lo que he dado en llamar, para la argumentación de este texto, holismo erótico, en un juego con los términos y con las perspectivas.

\section{Conclusiones para el debate: el holismo, la mujer y la complejidad}

"Por eso, en este Cosmos misterioso, maravilloso y terrible [...] reencontramos una Matria, la Biosfera, a la que estamos vinculados por una simbiosis orgánica de la que tomamos cada vez más conciencia" MORIN, 2003

"Sabemos desde ahora que el pequeño planeta perdido es más que un hábitat: es nuestra casa, home, Heimat, es nuestra matria y, más aún, es nuestra Tierra patria. Hemos aprendido que llegaremos a ser humo en los soles e hielo en los espacios. Desde luego, podremos irnos, viajar, colonizar otros mundos. Pero es aquí, en nuestra casa, donde están nuestras plantas, nuestros animales, nuestras muertes, nuestras vidas. Necesitamos conservar, necesitamos salvar la Tierra patria" MORIN, 1996 [la imprenta es mía]

La categoría epistemológica del holismo, así como la Ilamada teoría de la complejidad, constituyen herramientas heurísticas interesantes para abordar el mundo humano tal y como se nos presenta hoy, con sus paradojas y dilemas propios: intensamente globalizado y crecientemente regionalizado; políglota, babélico e intraducible; multicultural y transculturizado; ${ }^{38}$ imperial en su cumbre e insurgente en sus límites; etnificado, multimodal, 
39 Gustavo LINS RIBEIRO y Arturo ESCOBAR, 2006.

40 LINS RIBEIRO y ESCOBAR, 2006, p. 28ss y 31 .

${ }^{41}$ FISHER, 2000.

42 KÜBLER-ROSS, 1993.

${ }^{43}$ En KELLER, 1991.

44 No todas éstas investigadoras estudian 0 estudiaron la sexualidad, pero las perspectivas de sus investigaciones, así como sus mismos temas de estudio, se vinculan profundamente a la idea del holismo desde el paradigma de la complejidad. Los estudios de la médica tanatóloga Elizabeth Kübler-Ross sobre el duelo, pioneros en la disciplina, muestran una peculiaridad en el tratamiento de la cuestión precisamente originada en su consideración holista del fenómeno de la muerte humana. El ecofeminismo de la física y pensadora india Vandana Shiva, los estudios "emotivos" de tejidos citológicos ensayados por la Nobel de Medicina y Fisiología (1983) Barbara McClintock (cfr. KELLER, 1991) o los primeros estudios de lengua de signos y etología con grandes simios, encabezados igualmente por mujeres (Dian Fossey, Jane Goodall, Francine Patterson, Wendy Gordon, Deborah Foots, Mary Lee Abshire, Lyn White Miles...), son muestras apasionantes de una perspectiva holista de investigación y aproximación a la realidad, que tiene en cuenta tanto la razón y lo razonable como la emoción y la interdisciplinariedad, haciendo de la pluralidad y la originalidad en los planteamientos la riqueza y el fruto de su trabajo. proteico y generador de nuevos racismos... Las caras del prisma son tantas hoy que no cabe mirarlas sólo desde un lugar, ya sea éste la atalaya del consumado y autorizado pensamiento filosófico occidental, en el centro, ya sea desde los arbustos periféricos de los pensamientos y departamentos partisanos, en los bordes. ${ }^{39}$

Tanto como es pobre hoy considerar los estudios teóricos desde una sola perspectiva disciplinar, pues, resulta igualmente romo tratar de comprender la realidad desde una sola piel, un solo idioma ${ }^{40} \mathrm{o}$ una sola experiencia social, nacional, étnica y, por qué no, de sexo-género.

En este entramado difícil que nos toca vivir, de traslación dificultosa mas apasionante en sus desafíos, revolucionar la mirada sobre la sexualidad - y por ende sobre la sexualidad femenina -, revolucionar conceptualmente $y$ en la praxis las atribuciones y asunciones tradicionales ligadas a ciertas prácticas relativas a la sexualidad en general y la femenina en particular, pueda ser tal vez uno de los ejercicios más osados que nos quepa imaginar, por cuanto podría informar muchas otras esferas de relación e interacción humanas donde, como en tantos ámbitos, continúan primando -por desgracia a mi entender - unos modos de interacción planos, horizontales, autoritarios y exentos de la riqueza y el matiz que imprime la afectividad (categoría profundamente vinculada al concepto de holismo erótico).

Los cultos antiguos a la sexualidad y a la fertilidad femeninas, con la figura central de la diosa madre (Isis, lemanjá, Kuan Yin, María, tantas otras); la concepción de la sexualidad desde el milenario pensamiento tántrico; las corrientes espiritualistas medievales (clandestinas y prohibidas en su tiempo) tan populares hoy como la espiritualidad templaria... hasta los más modernos enfoques, teorías e investigaciones de estudiosas como Vandana Shiva, Helen Fisher, ${ }^{41}$ Elisabeth Kübler-Ross, ${ }^{42}$ Dian Fossey, Barbarah McClintock ${ }^{43}$ y tantas otras... ${ }^{44}$ desde todos estos lugares se arrojan luces distintas que nos hacen comprender, desde las categorías del holismo y de la complejidad, lo que pueda envolver la sexualidad femenina así como sus implicaciones en otras esferas, conductas y acciones de las mujeres en distintas épocas y contextos.

Cuando los estudiosos y analistas críticos contemporáneos se preguntan sobre las alternativas que hayan de ser creadas para alimentar un pensamiento de contrapoder, en el seno del rostro más duro de la globalización capitalista (vergonzante 'anti-redistribución' de la riqueza, estructuras políticas de influencia decreciente en un contexto donde el ciego imperativo del lucro económico adquiere a su vez un poder omnímodo, en el marco de un vacío de soberanía 
${ }^{45}$ Francisco PEÑAS ESTEBAN, 2005.

${ }^{46}$ Agradezco a José Ángel Martínez y a Héctor Arenas darme a conocer el término por primera vez, así como su mismo uso en medio de una pradera libre mapuche y al amor de un fuego compartido. internacional; imperialismo cultural desde occidente, etc), éstas se suelen pensar desde categorías generadas por la ciencia política, la sociología e incluso la antropología política. Se habla de la (re) distribución de la riqueza (y de la pobreza), pues; se habla de renta, de libertad incluso (desde los renovados y apasionantes conceptos de Sen), se habla de legitimidad política, derechos colectivos, derechos humanos, derechos de autodeterminación, interculturalidad... tantos otros 'nombres propios' de nuestro horizonte de reflexión crítica hoy, tantas otras 'nociones-paradigma' con las que levitamos desde la academia. ${ }^{45}$

Sin embargo, a la par de que se habla del respeto a los derechos humanos y de la revolución que esto supondría en la práctica si realmente se pudiera impeler a su cumplimiento (cosa que evidentemente no sucede, al menos hoy por hoy), no suele hablarse de algo mucho más pedestre, mucho más cotidiano, y mucho más en la médula espinal de lo que tal revolución supondría, y que es lo que podríamos llamar una segunda, o primera, revolución aparejada en los modos de relación de los seres humanos: ¿cómo van a dejar de ser horizontales, imperialistas, autoritarias y exentas en absoluto de las consideraciones más básicas de respeto y, por qué no, cariño y empatía humanos, las relaciones entre los países (por ejemplo, las relaciones entre EEUU y Venezuela o Cuba), si las relaciones análogas entre personas, entre los mismos vecinos, entre mujeres y hombres, no son transformadas de forma radical? Hay quienes llaman a esta revolución de la que hablo 'revolución de la ternura'. ${ }^{46}$

Es en esta debida consideración de lo micro y local a la par que de lo macro y global donde se juega la legitimidad, la certeza, la licitud de todas nuestras propuestas y de todas nuestras acciones; y para esta articulación de lo local y lo global devienen clave (entre otras varias posibles) las nociones del holismo y de la complejidad, tal y como aquí se han traído a colación. Ya sea que las apliquemos a la comprensión de la sexualidad femenina - tema que me ocupaba en esta disertación -; ya sea que desde los atributos de la sexualidad femenina comprendida por el holismo y la complejidad nos mudemos, así pertrechadas, a otras cuestiones donde aquellas lecciones se precisen igualmente; ya sea porque el mundo y la filosofía claman por una visión más amplia y comprometida, menos nacional y más interregional, más políglota y menos imperialista... de un modo u otro habremos de comenzar a ubicar las consideraciones éticas de nuestra responsabilidad sobre el planeta y sus habitantes por delante del interés personal o del lucro de las grandes empresas sin rostro.

Clausuro mi exposición, para entibiar un poquito el cierto tono apocalíptico a que nos hemos visto abocadas, 
47 FNUAP, en BOFF y MURARO, 2004, p. 200. citando el Informe Oficial de 2001 del Fondo de las Naciones Unidas para la Población: "La raza humana viene saqueando la Tierra de forma insostenible, y dar a las mujeres mayor poder de decisión sobre su futuro puede salvar el planeta de la autodestrucción". ${ }^{47}$

\section{Referencias bibliográficas}

ÁVILA GRANADOS, Jesús. "Los templarios y las vírgenes negras". In: ARROYO DURÁN, Fernando (eds. con TEMPLESPAÑA): Codex Templi. Los misterios templarios a la luz de la historia y de la tradición. Madrid: Santillana, 2005. p. 672-686 (capítulo XVIII).

Bhagavad Gîtâ. Cantar del Glorioso Señor. Edición de José J. de Olañeta. Barcelona: Los Pequeños Libros de la Sabiduría, 2005.

BOFF, Leonardo; MURARO, Rose Marie. Femenino y masculino: una nueva conciencia para el encuentro de diferencias. Madrid: Trotta, 2004

CARBONELL, Eudald; SALA, Robert. Aún no somos humanos [Propuestas de humanización para el tercer milenio]. Barcelona: Península Atalaya, 2002.

FEYERABEND, Paul K. Contra el método. Esquema de una teoría anarquista de conocimiento. Barcelona: Ariel, [1970] 1984.

FISHER, Helen. El primer sexo. Las capacidades innatas de las mujeres y cómo están cambiando el mundo. Madrid: Taurus, 2000.

GÓMEZ GARCÍA, Pedro. "La construcción de la antropología compleja: etapas y método". Gazeta de Antropología, n. 12, 1996.

Kama Sutra. Barcelona: Editorial Óptima, [aprox. Siglo III] 2000.

KELLER, Evelyn-Fox. Reflexiones sobre género y ciencia. Valencia: Alfons el Magnànim, [1985] 1991.

KERNER, Ian. Ellas llegan primero. El libro para los hombres que quieren complacer a las mujeres. Madrid: Santillana, 2006.

Koka Sastra. Barcelona: Ediciones Grupo Z, [aprox. Siglo XII] 1999.

KÜBLER-ROSS, Elizabeth. Sobre la muerte y los moribundos. Madrid: Grijalbo, [1969] 1993.

LINS RIBEIRO, Gustavo; ESCOBAR, Arturo. "Las antropologías del mundo. Transformaciones de la disciplina a través de los sistemas de poder". Universitas Humanística, n. 61 , p. 15-49, enero-junio 2006.

MASSÓ CANTARERO, Francisco. iPonte a vivir! Valores $y$ autoestima. Madrid: Asociación de Educación para la Salud, Eneida, 2001. 
MIGNOLO, Walter. "Compreensão humana e interesses locais: o Ocidentalismo e o argumento (latino)americano". In: . Histórias locais/projetos globais: colonialidade, poderes subalternos e pensamento liminar. Belo Horizonte: UFMG, 2005, p. 181-238.

MORIN, Edgar. "La relación antropo-bio-cósmica". Gazeta de Antropología, n. 11, 1995.

"El pensamiento ecologizado". Gazeta de Antropología, n. 12, 1996.

. "¿Sociedad mundo o imperio mundo? Más allá de la globalización y el desarrollo". Gazeta de Antropología, n. 19, 2003.

NIGHTINGALE, Florence. Notes of Nursing. What it is, and what it is not. Nueva York: D. Appleton and Company. Consultado en la web http://digital.library.upenn.edu/women/ nightingale/nursing/nursing.html, con fecha del 22 de diciembre de 2006.

OSHO. Tantra. Energía y éxtasis. Madrid: Edaf, 2003.

PEÑAS ESTEBAN, Francisco. "Procesos políticos y democratización en el África subsahariana: el pastel de la comunidad nacional". Conferencia pronunciada en el curso "DescoIonizar, intervenir, cooperar: África en el sistema internacional contemporáneo", celebrado en San Lorenzo de El Escorial del 18 al 22 de julio de 2005.

RORTY, Richard. El pragmatismo: una versión. Barcelona: Ariel, 2000.

SEN, Amartya Kumar. Nuevo examen de la desigualdad. Madrid: Alianza, 2000.

SERVAN-SCHREIBER, David. Curación emocional [Acabar con el estrés, la ansiedad y la depresión sin fármacos ni psicoanálisis]. Barcelona: Alianza, 2003.

WILSON, Edward O. Consilience: la unidad del conocimiento. Barcelona: Galaxia Gutenberg, 1999.

[Recebido em outubro de 2007 e aceito para publicação em setembro de 2008]

\section{Female Sexuality, Epistemological Holism and Complexity: Reflections for Contemporary Life}

Abstract: Starting from the recognition of the globalized world's complex condition and the need of a holistic consideration of its interconnected phenomena, this paper will present a defense of the complex perspective of the female sexuality, including the suggestion and defense of erotic holism as a possible source of proposals and solutions for the dilemmas posed by the 'global era'. The problematization of female sexuality and eroticism from the holistic paradigm of complexity will be a pretext for the consideration of the current global problems through a different and multidisciplinary perspective, by pointing out existing reductionist mono-explanatory paradigms.

Key Words: Epistemological Holism; Female Sexuality and Erotism; Globalization; Multidisciplinarity. 